\title{
TIGHT BINDING INHIBITORS OF XANTHINE OXIDASE
}

\author{
Russ Hille and Vincent Massey \\ Department of Biological Chemistry, University of Michigan, Ann Arbor, Michigan 48109, U.S.A.
}

\section{INTRODUCTION}

Xanthine oxidase catalyzes the oxidation of hypoxanthine to xanthine and xanthine to uric acid as follows

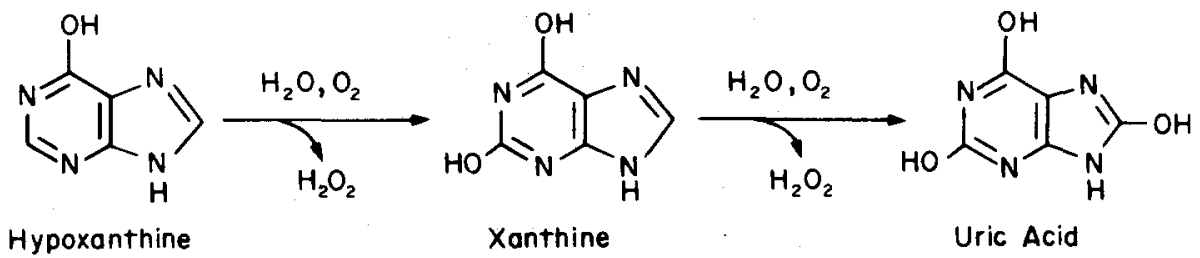

The enzyme is well-suited to carry out the catalysis of these oxidative reactions, containing as it does four redox-active sites: molybdenum, flavin adenine dinucleotide (FAD) and a pair of iron-sulfur centers of the ferredoxin type $\left(\mathrm{Fe}_{2} \mathrm{~S}_{2}\right)$. The purine substrates interact with the enzyme at the molybdenum site of xanthine oxidase and oxygen at the flavin site. The two metabolic reactions above constitute the final steps of purine catabolism in primates and as such play an important role in determining the in vivo steady state levels of the various purines, particularly that of uric acid. The introduction of potent inhibitors of xanthine oxidase has proven a clinically effective way to control the hyperuricemia associated with gout (Elion et al., 1963; Duggan et al., 1975; cf. Rundles et al., 1969, for a review) and attenuate the activity of mercaptopurinol and other antileukemic drugs (Rundles et al., 1963). In addition, in vitro studies on the mechanism of action of these compounds have shed considerable light on the properties of the enzyme itself (e.g. Massey et al., 1970a,b). This review will concern itself primarily with such in vitro studies, and the reader is referred to the review by Rundles et al., for clinical considerations. Two review articles on the general properties of xanthine oxidase have appeared recently (Massey, 1973; Bray, 1975).

Potent inhibitors of xanthine oxidase can be divided into two broad categories: (1) molecules which are analogs of the purine substrates to a greater or lesser extent and (2) molecules which bear no particular structural relationship to the physiological substrates. The former group consists of pyrazolo[3,4-d]pyrimidines (alloxanthine being the most important among them), pterins such as 6-pteridylaldehyde, and certain other aromatic heterocycles. Included in the latter group are cyanide, arsenite, and methanol, compounds which do not inhibit xanthine oxidase exclusively, but nonetheless interact very specifically with the enzyme. Both classes of inhibitors act at or very near the molybdenum site of the enzyme, or with the active site cyanolysable sulfur atom (cf. Section 3.1), and interfere with the reaction of enzyme with the reducing substrates (hydroxypurines) rather than oxygen. The following discussion will deal first with the purine analogs, about which a good deal is known, and then take up the second class of inhibitors, about which a good deal less is understood. 


\section{PURINE ANALOGS}

\subsection{Allopurinol and Alloxanthine}

\subsubsection{Mechanism of Action}

Pyrazolo[3,4-d]pyrimidines were first reported to be inhibitors of xanthine oxidase by Feigelson et al. (1957). Later clinical and enzymological studies by Elion and coworkers established that allopurinol (4-hydroxypyrazolo[3,4-d]pyrimidine) was a particularly effective inhibitor in vivo as well as in vitro (Elion et al., 1963, 1966; Rundles et al., 1963). It was further shown that allopurinol was enzymatically oxidized to the 4,6-dihydroxy compound alloxanthine (Elion et al., 1966). Prior incubation of xanthine oxidase with allopurinol resulted in total loss of activity in xanthine-oxygen oxidoreduction assays, whereas incubation with alloxanthine resulted in no initial inhibition, but progressive inactivation during the course of the assays (Elion, 1966). These findings suggested that inactivation was due to inhibitor binding to an intermediate in the catalytic cycle.<smiles>Oc1ncnc2[nH]ccc12</smiles>

Allopurinol

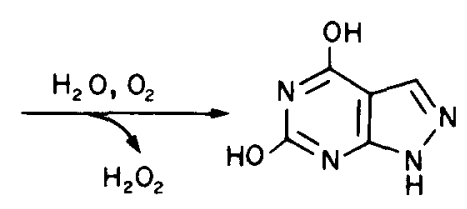

Alloxanthine

Subsequent work by Massey and coworkers (Massey et al., 1970a,b) established that allopurinol inhibited xanthine oxidase by forming a very tight complex with reduced molybdenum at the active site after having been oxidized by the enzyme to alloxanthine. When xanthine oxidase was incubated with allopurinol under anaerobic conditions, significant reduction of the enzyme was observed spectrophotometrically (Fig. 1, curve 2). On admission of air the enzyme became reoxidized, but the spectrum of the inactive material obtained (Fig. 1, curve 3) differed from that of untreated enzyme (curve 1). An

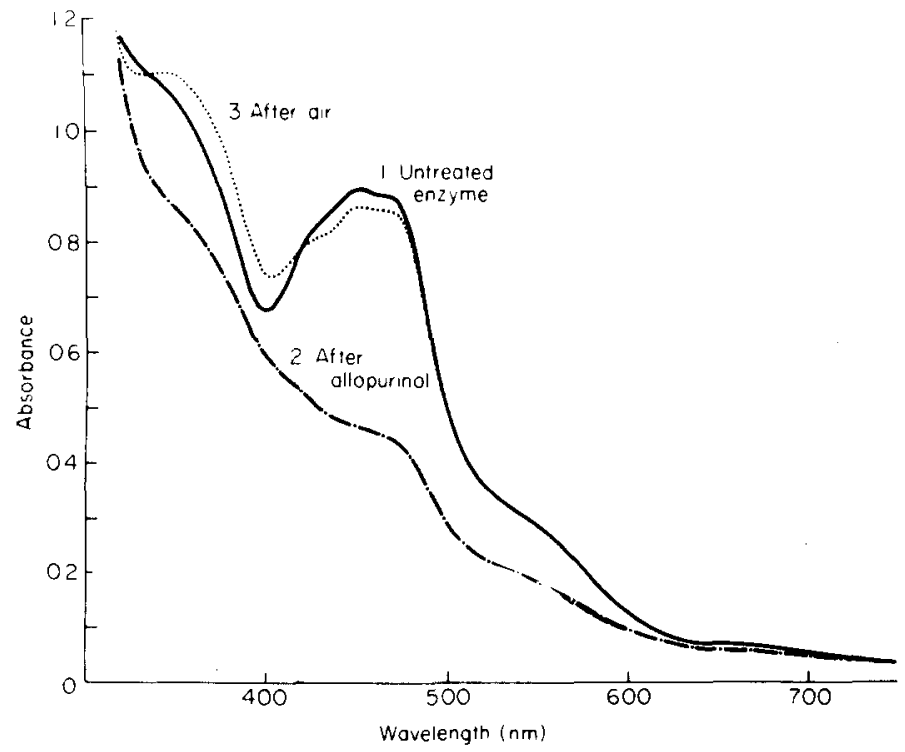

FIG. 1. Effect of allopurinol on the spectrum of xanthine oxidase. Curve 1, untreated enzyme, $2.38 \times 10^{-5} \mathrm{M}$ with respect to FA.D, in $0.1 \mathrm{M}$ pyrophosphate $\mathrm{pH} 8.5,25^{\circ} \mathrm{C}$. Curve 2 , spectrum recorded $5 \mathrm{~min}$ after the addition of $1.67 \times 10^{-4} \mathrm{M}$ allopurinol anaerobically. The spectrum remained unchanged over a period of $2 \mathrm{hr}$. Curve 3 , immediately after mixing with air; further addition of allopurinol or xanthine anaerobically resulted in no spectral changes over a period of $2 \mathrm{hr}$ (From Massey et al., 1970b). 
identical spectrum could be obtained if alloxanthine plus xanthine was used in place of allopurinol, implicating alloxanthine as the actual inhibiting species. In both cases, the difference between the spectra taken before and after admission of air was identical to the difference between the spectra of oxidized enzyme and enzyme reduced by xanthine (Fig. 2). This strongly suggested that the iron-sulfur and FAD chromophores of the enzyme were unaltered and that alloxanthine was interacting at the molybdenum site. Furthermore, when the inhibited reoxidized enzyme was incubated with potassium ferricyanide, an additional two electron equivalents per active site were extracted from the enzyme, resulting in full recovery of activity and a return of the spectrum to that of native enzyme. As the iron-sulfur and FAD sites were oxidized at the outset, this indicated that the molybdenum was still reduced in the inhibitory complex. This inhibitory complex between alloxanthine and reduced molybdenum precludes catalytic reaction involving the molybdenum site, but has no effect on the NADH-ferricyanide activity of xanthine oxidase (Elion, 1966), an activity known to involve only the iron-sulfur and FAD sites of the enzyme (Komai et al., 1969).

Alloxanthine binding was found to be so tight that even at an enzyme concentration of $5 \times 10^{-6} \mathrm{M}$ it bound to the reduced enzyme stoichiometrically (Massey et al., 1970a). This permitted its use in functional site titrations of protein samples and led to the recognition of appreciable amounts $(20 \%$ or more) of inactive xanthine oxidase in apparently homogenous enzyme preparations. An affinity chromatography technique for resolving active and inactive xanthine oxidase was subsequently developed that relied on the tight binding of pyrazolo[3,4-d]pyrimidines to functional enzyme in the reduced state (Edmondson et al., 1972).

The orientation of the nitrogen atoms within substrate analogs is apparently critical for the expression of this type of xanthine oxidase inhibition. While a series of pyrazolo[3,4-d]pyrimidines all exhibited behavior like that of allopurinol in inhibiting the enzyme (Figs 2 and 3), a group of pyrazolo[4,3-d]pyrimidines, triazolopyrimidines and pyrrolopyrimidines did not (Massey et al., 1970b). These latter compounds were found to be substrates for the enzyme but in no case were spectral perturbations similar to those of the pyrazolo[3,4-d]pyrimidines observed, nor was enzyme inhibition detected.

A key question remaining as regards the mechanism of inhibition of xanthine oxidase by allopurinol and other pyrazolo[3,4-d]pyrimidines has to do with the large number of turnovers (thirty or more) required to effect inhibition during aerobic turnover (Massey

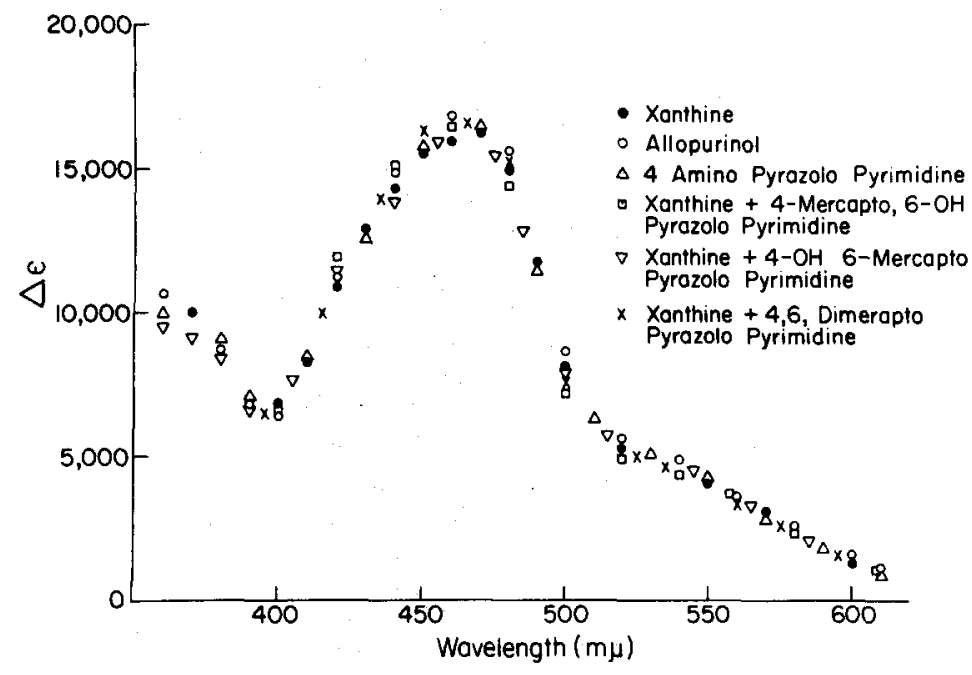

FIG. 2. Difference spectra (expressed as $\Delta \xi$ based on concentration of enzyme-bound flavin) between air-reoxidized enzyme and enzyme reduced as indicated. With xanthine as reductant the difference calculated was between oxidized enzyme and the spectrum produced immediately after addition of xanthine. The difference spectra obtained with the pyrazolo[3,4-d]pyrimidines was, for example, that between curves 3 and 2 of Fig. 1 (from Massey et al., 1970b). 


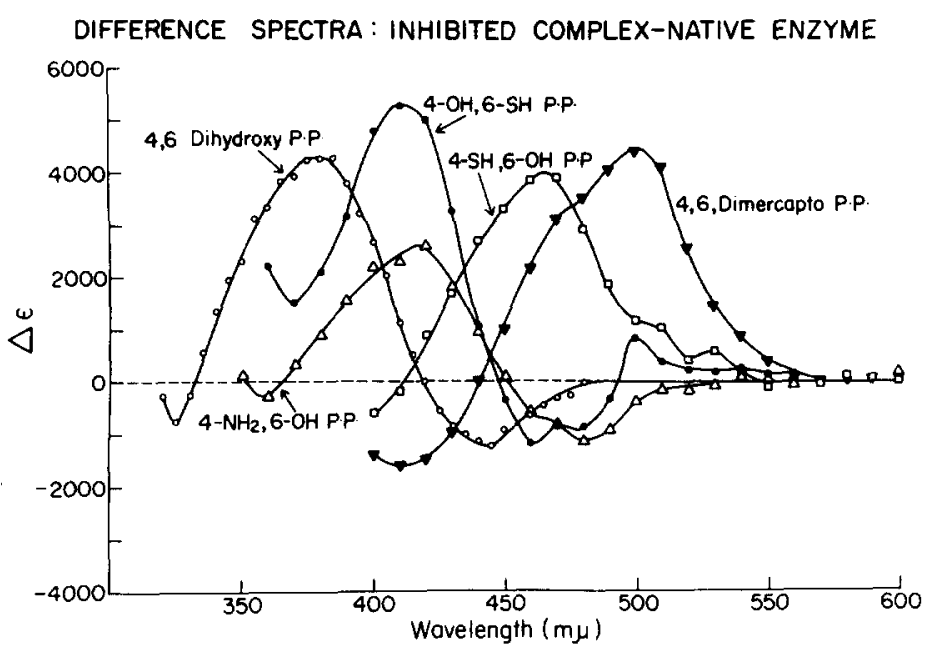

FIG. 3. Difference spectra between xanthine oxidase inactivated with various pyrazolo[3,4-d]pyrimidines and native enzyme. The spectra represent, for example, the difference between curves 3 and 1 of Fig. 1.

et al., 1970a ; Spector and Johns, 1970). Why is the enzyme-product complex of alloxanthine with reduced enzyme which is formed in the first turnover unable to prevent subsequent turnovers? Clearly the dissociation constant for the first several alloxanthine molecules formed must be much greater than that for alloxanthine participating in the ultimate inhibitory complex. A clue lies in the observation that, along with a pair of electrons, a proton is transferred from substrate to molybdenum in the early steps of catalysis (Edmondson et al., 1973). Thus the initial complex on formation of product would be alloxanthine $\cdot \mathrm{Mo}^{\mathrm{IV}} \cdot \mathrm{H}^{+}$. The likely sequence of events in the decay of this species is alloxanthine dissociation followed by redistribution of electrons from molybdenum to iron-sulfur and flavin sites, and proton dissociation. Subsequent rebinding of alloxanthine to the molybdenum site of fully reduced enzyme would give rise after a number of turnovers to a complex not containing a proton, and conceivably having a much lower $K_{d}$ for alloxanthine. This scheme, while highly speculative, provides a mechanistically reasonable explanation for the observed delay in the onset of inhibition by allopurinol.

\subsubsection{Clinical Considerations}

Allopurinol has been found to be a clinically effective, well-tolerated drug in the treatment of hyperuricemia associated with gout (Elion et al., 1963; Rundles et al., 1969; Yu and Cutman, 1964). Doses as high as 700-1000 mg per day can be administered for extended periods in relative safety to maintain serum and urinary urate levels well below the limit of solubility of $7 \mathrm{mg} \%$ (Rundles et al., 1963; Goldfinger, 1971). Significantly, allopurinol does not appear to induce synthesis of xanthine oxidase or to shorten its in vivo half-life, nor does it increase the steady state levels of the various purine pools (Rundles et al., 1969; Goldfinger, 1971). Side-effects are rare, but include leukopenia, thrombocytopenia, renal impairment, dermatitis, rashes and mild gastrointestinal disorders (Rundles et al., 1969; Chalmers et al., 1969). In general, it appears that withdrawal of treatment results in amelioration of symptoms when they occur.

It has been established however, that allopurinol can condense with phosphoribosylpyrophosphate in a reaction catalyzed by IMP-pyrophosphate phosphoribosyltransferase to form a nucleotide with anti-metabolic potential (McCollister et al., 1964; Chalmers et al., 1969). Conversion to the nucleoside by purine nucleoside phosphorylase has also been reported (Krenitsky et al., 1967). Because the effects of these compounds are unknown and could well be deleterious after long periods of time, efforts to find new drugs 
equally potent as inhibitors of xanthine oxidase but lacking reactivity in these undesirable side reactions have beeen made.

\subsection{Other Substrate Analog Inhibitors of Xanthine Oxidase}

Historically, the first potent inhibitor of xanthine oxidase discovered was a breakdown product of folic acid (Kalckar and Klenow, 1948a,b), later identified as 2-amino-4-hydroxy-6-formylpteridine, commonly known as 6-pteridylaldehyde (Kalckar et al., 1948). Lowry et al. (1948) determined the $K_{i}$ for this compound to be $6 \times 10^{-10} \mathrm{M}$ and showed that it was slowly converted by the enzyme to 6-pteridyl carboxylic acid.

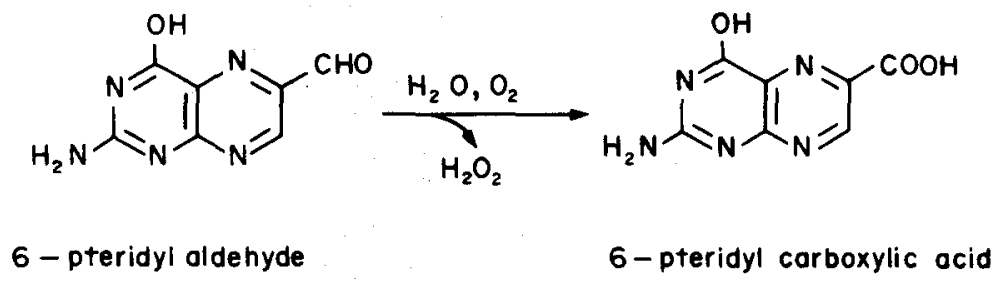

In at least one instance (Oster, 1976) folic acid has been mistakenly used clinically to treat hyperuricemia, the effective agent presumably being 6-pteridylaldehyde produced from catabolism of folic acid (or present as an impurity in the folic acid to begin with). Recent studies by Kaplan (1980) indicate that folic acid itself is probably not an effective inhibitor of xanthine oxidase.

The reaction of 6-pteridylaldehyde with xanthine oxidase may be followed kinetically by observing the increase in long-wavelength absorbance $\left(\lambda_{\max }=620 \mathrm{~nm}\right)$ on binding of inhibitor to enzyme (Fig. 4). Results from this laboratory (Massey, unpublished results)

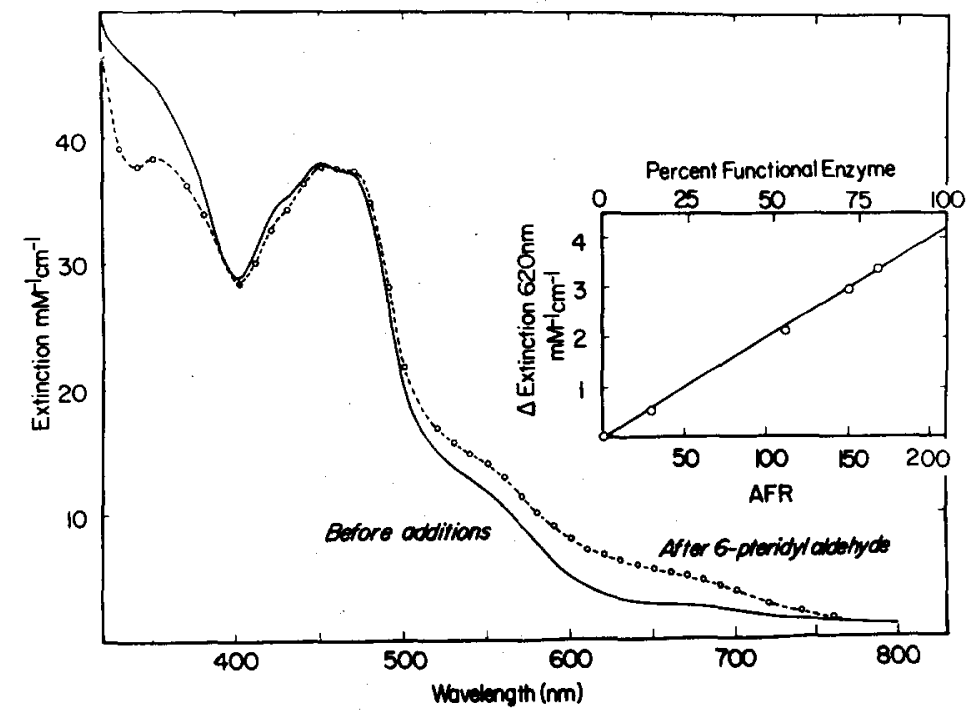

Fig. 4. The effect of 6-pteridylaldehyde on the spectrum of xanthine oxidase. Solid line; native enzyme, in $0.1 \mathrm{M}$ pyrophosphate $\mathrm{pH} 8.5,25^{\circ} \mathrm{C}$. Dashed line; after the addition of 6-pteridylaldehyde, aerobically. Inset; the relationship between the extinction change observed at $620 \mathrm{~nm}$ on addition of 6-pteridylaldehyde to the fraction of active enzyme in solution. AFR represents the activity-to-flavin ratio, a measure of functional enzyme activity with 212 corresponding to fully active enzyme. It is defined as the change in absorbance per min at $295 \mathrm{~nm}$ in a $3 \mathrm{ml}$ reaction volume divided by the absorbance at $450 \mathrm{~nm}$ of the xanthine oxidase used in the assay, under the standard conditions of $100 \mu \mathrm{M}$ xanthine, $250 \mu \mathrm{M} \mathrm{O}$, in $0.1 \mathrm{M}$ pyrophosphate, $\mathrm{pH} 8.5,25^{\circ} \mathrm{C}$. 
indicate that the species giving the long wavelength absorption arises from a pre-equilibrium having a $K_{d}$ of $5 \times 10^{-5} \mathrm{M}$ and appears at a limiting rate of $20 \mathrm{~s}^{-1}$ at high pteridylaldehyde concentrations (Fig. 5)

$$
\mathrm{E}+\mathrm{PTA} \stackrel{\kappa_{1}=5 \times 10^{-} \mathrm{u}}{\rightleftharpoons} \mathrm{E} \cdot \mathrm{PTA} \stackrel{k=20,1}{\rightleftharpoons} \mathrm{E} \cdot \mathrm{PTA}^{*}
$$

where E-PTA* represents the absorbing species. A rate on the order of $2 \times 10^{-3} \mathrm{~s}^{-1}$ for the reverse reaction of the second step would account for the observed overall $K_{i}$ of $10^{-9} \mathrm{M}$. The amount of absorbance change observed on addition of pteridylaldehyde to enzyme is directly proportional to the specific activity of the enzyme. Prior treatment with cyanide, known to chemically alter the active site by removing an essential sulfur atom as $\mathrm{SCN}^{-}$(cf. Section 3.1.), is found to prevent the appearance of the long wavelength absorption. This in conjunction with the observation that the same absorbance change was observed on binding of 6-pteridylaldehyde to deflavo enzyme (eliminating the possibility of flavin radical as the absorbing species) suggests involvement. of the molybdenum site (or the cyanolysable sulfur) in the structure of the chromophore. Binding of 6-pteridylaldehyde to xanthine oxidase is so tight that substoichiometric amounts of inhibitor were found to inhibit the enzyme completely, thus providing the first evidence for the existence of nonfunctional forms of xanthine oxidase (Lowry et al., 1948). It is possible that the long-wavelength absorbing species represents a transient covalent intermediate in the catalytic cycle (cf. Fig. 6, intermediate II), dramatically stabilized in the case of 6-pteridylaldehyde (Davis, 1980).

Pursuing another line. Baker and Wood (1967) showed that 9-phenylguanine inhibited xanthine oxidase some 140 times more effectively than did 9-methylguanine and that the aromatic interaction with enzyme was hydrophobic rather than charge-transfer in nature. Further investigation into this hydrophobic interaction led to the tailoring of active-site directed irreversible inhibitors of xanthine oxidase (Baker and Wood, 1968a,b; Baker et al., 1968). These compounds contained good leaving groups on the aromatic substituents, rendering them susceptible to nucleophilic attack by basic amino acid residues near the active site of the enzyme and leading to covalent modification of the protein. Among the most effective of these inhibitors was the following compound

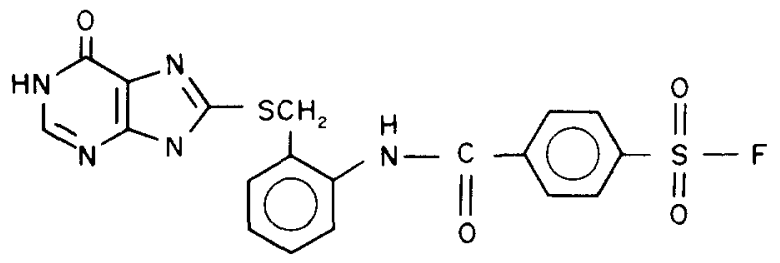

This compound was found to exhibit an $I_{50}$ of $10^{-7} \mathrm{M}$ (under the assay conditions of $8 \mu \mathrm{M}$ xanthine and $250 \mu \mathrm{M}$ oxygen) and greater than $80 \%$ covalent inhibition after $20 \mathrm{~min}$ of incubation. The mode of covalent attachment to the enzyme was not determined in these studies, but on the basis of the current understanding of the enzyme mechanism (Fig. 6), it is tempting to speculate that the nucleophile at the enzyme active site is a persulfide residue (cf. Section 3.1.) important in the catalytic cycle. The clinical usefulness of these compounds is uncertain due to likely interactions of these compounds with other enzymes involved in purine metabolism (Baker and Wood, 1968a,b) and possible negative effects on the in vivo stability of xanthine oxidase as a result of covalent modification.

Recently a comprehensive survey of potential inhibitors of xanthine oxidase among substituted imidazoles and triazoles was undertaken by Baldwin et al. $(1975,1977)$. Typical of the compounds found most effective in in vitro enzyme assays were 3-(3-pyridyl)5-(4-pyridyl)-1.2,4-triazole (I) and 2-(4-pyridyl)-4,5-dicyanoimidazole (II). Both of 
<smiles>C1=NC=C(c2n[nH]c(-c3ccncc3)n2)CC1</smiles>

I<smiles>N#Cc1nc(-c2ccncc2)[nH]c1C#N</smiles>

II

these compounds were some 100 -fold more effective than allopurinol, with $I_{50}$ values at $300 \mu \mathrm{M}$ hypoxanthine and $250 \mu \mathrm{M}$ oxygen of $2 \times 10^{-8} \mathrm{M}$, compared with $I_{50}$ for allopurinol of $3 \times 10^{-6} \mathrm{M}$. Among the triazoles tested it was found that 4-pyrimidinyl, 4-pyridyl, 5-quinolyl or several halogenated benzene derivatives could be substituted for the 3-pyridyl residue at position 3 without significant loss of inhibitory capacity, but substitution of 2-pyridyl or 2-pyrimidinyl resulted in a thousand-fold decrease in $I_{50}$ (Baldwin et al., 1975). As was the case with the pyrazolo[3,4-d]pyrimidines, the relative positions of the nitrogen atoms within the heterocycles are apparently critical for the expression of inhibitory activity. In the imidazole series, nitro or carboxyl groups were acceptable substitutes for the cyano group at positions 4 and 5 (resulting in only a slight loss of inhibition) but amido or carboxymethyl groups were not. For both imidazoles and triazoles, a pyridyl function and a free imino group in the five-membered ring were required for inhibitory activity. These compounds were apparently not hydroxylated by xanthine oxidase (Duggan et al., 1975).

Springer et al. (1976) reported the inhibition of xanthine oxidase by 5,7-dihydroxypyrazolo[1,5- $x]$ pyrimidines having aromatic substituents at position 3<smiles>[R]c1cnn2c(O)cc(O)nc12</smiles>

The most potent of these inhibitors, with $\mathrm{R}=$ benzyl, 3-pyridyl or 1-naphthyl, exhibited $K_{i}$ s 50 -fold less than allopurinol $\left(2 \times 10^{-8} \mathrm{M}\right.$, versus $10^{-6} \mathrm{M}$ for allopurinol). These workers compared this with a $K_{i}$ for allopurinol of $10^{-6} \mathrm{M}$, but $10^{-10} \mathrm{M}$ appears to be a better estimation of that value (Spector and Johns, 1970). Inhibition was found to be of

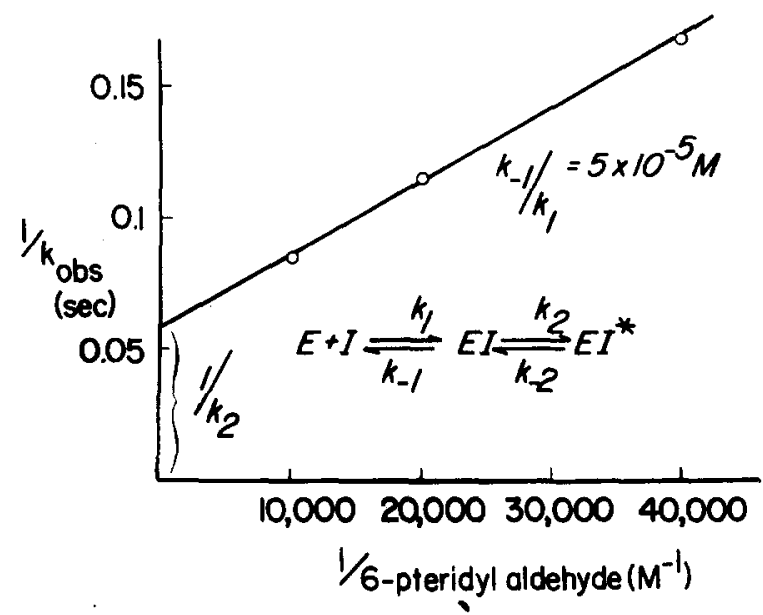

FIG. 5. The dependence of the rate of formation of the long wavelength absorbance from Fig. 4 on 6-pteridylaldehyde concentration. From the intercept and slope of the double reciprocal plot values of $20 \mathrm{~s}^{-1}$ for $k_{2}$ and $5 \times 10^{-5} \mathrm{M}$ for $k_{-1} / k_{2}$ can be determined. respectively. 


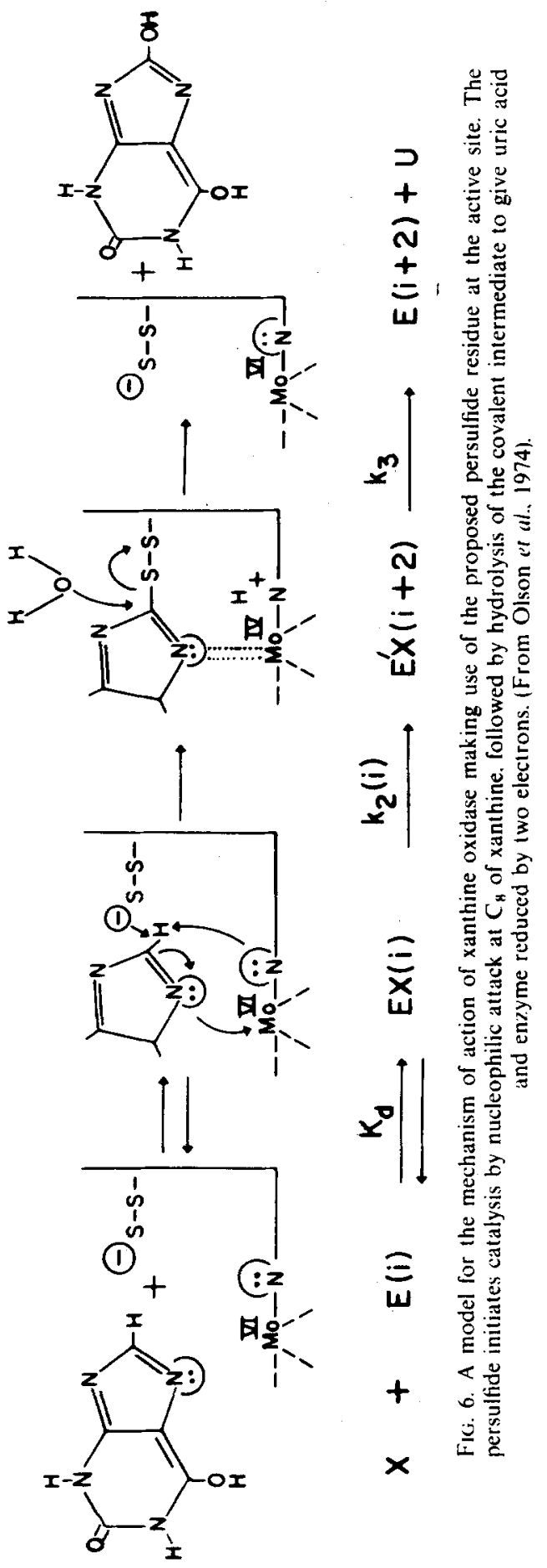


the non-competitive variety, although as Cha points out (Cha, 1975) apparently noncompetitive inhibition is to be expected regardless of the nature of the enzyme-inhibitor interaction, given the very tight binding of these inhibitors.

In conducting studies of this general nature, two considerations must be kept in mind. First, $I_{50}$ values reflect only an apparent $K_{i}$ at the given substrate concentrations used in the assay. In the absence of additional information it is impossible to extrapolate such data to obtain values for the true $K_{i}$, the parameter that accurately reflects the affinity of the inhibitor for the enzyme to which it binds. Cha has discussed this and other problems associated with the study of tight-binding inhibitors in general (Cha, 1975) and the interaction of allopurinol and alloxanthine with xanthine oxidase in particular (Cha et al., 1975). In brief, the relationship of $I_{50}$ to $K_{i}$ is shown to depend on the type of inhibition and may be further complicated by failure to achieve a steady-state condition in the course of enzyme assays. The second consideration is that all comparisons of prospective drugs seem to be made with allopurinol. In fact, alloxanthine (the product of enzyme oxidation of allopurinol) is the actual inhibitor, and its dissociation constant with reduced enzyme is about $10^{-10} \mathrm{M}$ (Massey et al., 1970a; Spector and Johns, 1970), considerably less than the $I_{50}$ value of $10^{-6} \mathrm{M}$ for allopurinol used for comparative purposes. Such being the case, the apparent attractiveness of many inhibitors becomes greatly diminished when compared to alloxanthine.

\section{OTHER INHIBITORS OF XANTHINE OXIDASE}

\subsection{Cyanide}

Cyanide was first shown to inhibit xanthine oxidase by Szent-Gyorgyi (1926). Fridovich and Handler (1958) reported that ${ }^{14} \mathrm{CN}^{-}$bound to the enzyme with a stoichiometry of one molar equivalent per active site, but it was subsequently shown by Massey and Edmondson (1970) that this was not the source of inactivation. Rather, cyanide reacted with the enzyme to release an essential sulfur atom as thiocyanate. Activity could be recovered to a significant extent by incubation with $\mathrm{Na}_{2} \mathrm{~S}$. When $\mathrm{Na}_{2}{ }^{35} \mathrm{~S}$ was used, a second treatment with $\mathrm{CN}^{-}$produced ${ }^{35} \mathrm{SCN}^{-}$. Using an affinity column procedure based on the tight binding of pyrazolopyrimidines to reduced enzyme, Edmondson $e t$ al. (1973) were able to separate active and inactive xanthine oxidase, and show that the inactive enzyme found in standard preparations was identical to the cyanide-treated, or desulfo, species.

On the basis of the chemical evidence, Massey and coworkers (Massey and Edmondson, 1970; Olson et al., 1974) have propsed that xanthine oxidase contains a persulfide group at its active site. This persulfide is postulated to act as a nucleophile in the course of catalysis, as shown in Fig. 6, and be susceptible to cyanolysis in a reaction typical of persulfides

$$
\mathrm{R}-\mathrm{SS}^{-}+\mathrm{CN}^{-} \rightarrow \mathrm{RS}^{-}+\mathrm{SCN}^{-}
$$

In order to explain the observation that treatment with cyanide under anaerobic conditions results in enzyme reduction, a nearby thiol is proposed that spontaneously forms a disulfide with the product of cyanolysis (Massey and Edmondson, 1970). This second thiol would also play a part in the binding of arsenite, another inhibitor of xanthine oxidase (see below). It is known, however, that fully reduced enzyme is not inactivated by cyanide (Fridovich and Handler, 1958), presumably due to a compulsory transfer of electrons to Mo in the course of inactivation. Disulfide formation would therefore have to be an obligatory step in cyanide inactivation according to the persulfide scheme. There appears to be no compelling reason why this must be so. In addition, the essential sulfur site exhibits certain properties difficult to reconcile with persulfides. For example, it is stable at low $\mathrm{pH}$, as evidenced by the fact that native and desulfo enzyme release the same amount of acid-labile sulfur (Massey and Edmondson, 1970), and is 
unreactive with nucleophiles such as hypotaurine, to which the active site should be accessible.

Two alternate proposals regarding the chemical nature of the essential sulfur site have been put forward recently. Coughlan (1977) has proposed a cysteinyl residue in complex with molybdenum, which is susceptible to nucleophilic attack by $\mathrm{CN}^{-}$(Fig. 7A). The scheme accounts for the observed stoichiometry of one thiocyanate produced per active site, the generation of reducing equivalents in the course of inactivation, and at first glance, the known fixation of $\mathrm{CN}^{-}$to the enzyme (Fridovich and Handler, 1958; Coughlan et al.. 1969). However, the scheme predicts one $\mathrm{CN}^{-}$fixed for each $\mathrm{SCN}^{-}$produced. This is not in agreement with results of Massey and Edmondson (1970) which showed that after one hour in the presence of $9 \mathrm{mM} \mathrm{K}^{14} \mathrm{CN}$, the enzyme was fully inactivated and the stoichiometry of $\mathrm{S}^{14} \mathrm{CN}^{-}$released per active site was $0.96: 1.0$, but the amount ${ }^{14} \mathrm{CN}^{-}$fixed to protein was only $0.39: 1.0$. In addition, to explain the observation of naturally occurring inactive enzyme, and its activation by $\mathrm{Na}_{2} \mathrm{~S}$, the highly speculative scheme in Fig. 7B must be proposed. Apart from the uncertain chemistry, it is not clear that the dehydroalanine and cyanoalanine species proposed for naturally occurring and cyanide inactivated enzyme forms, respectively, would be expected to give the same absorption spectra, as is observed (Edmondson et al., 1972). Also, as was the case with the persulfide model, there is no clear reason from this scheme why prior reduction of the molybdenum should prevent inactivation.

A third proposal has been considered by Bray and coworkers (Gutteridge et al., 1978; Bray et al., 1979). In this model the essential sulfur atom exists as a terminal sulfo ligand to the molybdenum. Reaction of this species with $\mathrm{CN}^{-}$would follow the scheme shown in Fig. 8 and account for the $\mathrm{SCN}^{-}$and redox equivalent stoichiometry that is observed experimentally. Prior reduction of the molybdenum site would probably give rise to a species with the following structure, due to the large shifts of $\mathrm{pK}$ of Mo ligands generally associated with changes in redox state of molybdenum (Steifel, 1977)

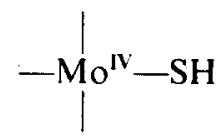

This species would not be expected to be susceptible to $\mathrm{CN}^{-}$because, on the basis of the model. Mo would have to be reduced beyond the IV valence state in the course of inactivation. Electron paramagnetic resonance data provide further evidence, albeit somewhat indirect, in favor of this model. Both native and desulfo xanthine oxidase exhibit $\mathrm{Mo}^{\mathrm{v}}$ signals strongly coupled to protons, but on dilution into $\mathrm{D}_{2} \mathrm{O}$ the proton of the desulfo enzyme exchanges some 200 -fold more slowly than the proton of the native enzyme. Assuming proton association is diffusion-controlled for both forms of the

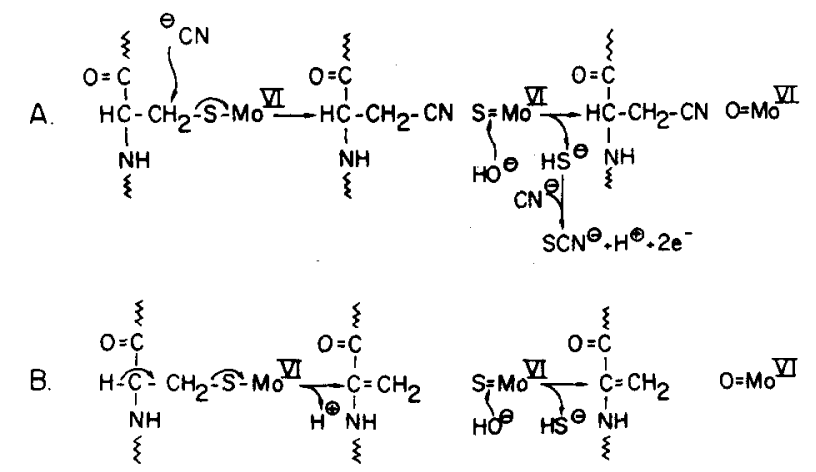

FIG. 7. A model for the active site of xanthine oxidase based on cysteine as the source of cyanolysable sulfur. A: scheme proposed for the cyanolysis reaction. $B$ : scheme proposed to account for naturally occurring inactive enzyme (from Coughlan. 1977). 


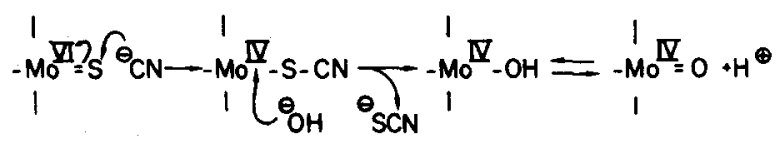

FIG. 8. Scheme for the cyanolysis of a Mo $=\mathrm{S}$ complex.

enzyme, the above difference in rates of dissociation corresponds to a difference in $\mathrm{pK}$ of 2 , with native enzyme being more acidic. This is of the order expected if the protons were binding directly to sulfo and oxo ligands in native and desulfo enzyme, respectively, given the greater acidity of sulfur-bound protons compared to oxygen-bound ones (Gutteridge et al., 1978; Steifel, 1977). Similarly, the much lower redox potential of the molybdenum site of desulfo xanthine oxidase compared to that of native enzyme $(-460 \mathrm{mV}$ vs $-355 \mathrm{mV}$, respectively; Cammack et al., 1976) may be held as consistent with the substitution of oxygen for sulfur in the desulfo species. Recent data from extended X-ray absorption fine structure (EXAFS) experiments support the notion that the sulfur lies in the coordination sphere of molybdenum (Bordas et al., 1980). In this method, the attenuation of X-ray absorption due to the presence of nuclei in the vicinity of the absorbing nucleus (in this case molybdenum) is simulated empirically using parameters obtained from studies on model compounds of known three dimensional structure. EXAFS has proven extremely sensitive to the type of atom and its distance from the absorbing nucleus, and a comparison of the EXAFS spectra for native and desulfo xanthine oxidase clearly indicates a difference in the molybdenum environment of the two enzyme forms. Unfortunately, while this difference reflected changes in xanthine oxidase coordination at a distance consistent with those expected for the conversion of $\mathrm{Mo}=\mathrm{S}$ to $\mathrm{Mo}=\mathrm{O}$, simulations were not able to demonstrate unambiguously the loss of a sulfur atom and the gain of an oxygen atom in the coordination sphere of xanthine oxidase on treatment with cyanide. In a comparative study of the EXAFS spectra of sulfite oxidase and xanthine oxidase with a series of model compounds (Berg et al., 1979; Tullius et al., 1979) it was found that sulfite oxidase yielded a spectrum virtually identical to that of the compound shown in Fig. 9. Xanthine oxidase gave a somewhat different, although still very similar EXAFS spectrum. The xanthine oxidase sample used in these studies, however, was not fully active and therefore heterogeneous as regards the molybdenum center. The EXAFS spectrum of the desulfo form (Bordas et al., 1980) appears to resemble more closely that of the model compound (Tullius et al., 1979) although direct comparison of spectra from the two references is difficult.

The observation most difficult to explain with the $\mathrm{Mo}=\mathrm{S}$ model comes from experiments using a Neurospora mutant that synthesizes aponitrate reductase but not apparently, an essential molybdenum cofactor (Ketchum et al., 1970; Nason et al., 1971). Rajagopalan and coworkers have reported that the molybdenum cofactor isolated by acid treatment from cyanide-treated as well as native xanthine oxidase is capable of restoring nitrate reductase activity to the Neurospora apoenzyme (Hainline et al., 1979). This result is inconsistent with the notion that the essential sulfur is an integral part of a molybdenum cofactor as it must be if it exists as $\mathrm{Mo}=\mathrm{S}$. It may be possible. however. to

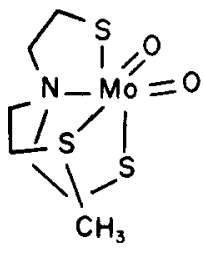

FIG. 9. The structure of $\mathrm{MOO}_{2}\left[\left(\mathrm{SCH}_{2} \mathrm{CH}_{2}\right)_{2} \mathrm{NCH}_{2} \mathrm{CH}_{2} \mathrm{SCH}_{3}\right]$, a model for the active site of xanthine oxidase. 
reconcile these results with the $\mathrm{Mo}=\mathrm{S}$ model. Neither sulfite oxidase (which can also provide molybdenum cofactor active in the Neurospora reconstitution experiment) nor nitrate reductase appear to be inhibited by cyanide in the same way as xanthine oxidase; i.e. by releasing sulfur in the form of thiocyanate. It is conceivable that $\mathrm{Mo}=\mathrm{O}$, formed spontaneously from $\mathrm{Mo}=\mathrm{S}$ in the acid extraction step in the case of native xanthine oxidase and occurring naturally in the case of sulfite oxidase, is the species responsible for the reconstitution of nitrate reductase activity and that the sulfur needed for xanthine oxidase activity is not required. While this would offer an explanation for the striking similarity in the ESAFS spectra of sulfite oxidase and desulfo xanthine oxidase to the model compound of Fig. 9, and the slight difference in the case of native xanthine oxidase, more work is clearly needed. It is difficult to explain, for example, the wellestablished inhibition of cyanaolysis by arsenite (Rajagopalan and Handler, 1964; Massey and Edmondson, 1970) in terms of the $\mathrm{Mo}=\mathrm{S}$ model. The only known mechanism of action of arsenite is to complex very tightly to dithiols, and the extent to which $\mathrm{Mo}=\mathrm{S}$ would exhibit thiot character is unclear. While a prototropic equilibrium such as discussed above might be invoked to generate $\mathrm{Mo}^{\mathrm{IV}}-\mathrm{SH}$, this species, if formed, does not react with Kenyon's reagent [methylmethanethiosulfonate (Smith et al., 1975)] in the pH range 7-10 to result in loss of activity ( $R$. Hille, unpublished data), nor with DTNB (Massey et al., 1970a) and so cannot be considered to have the general properties of a thiol.

\subsection{Methanol AND Formaldehyde}

Methanol inhibits xanthine oxidase when incubated in the presence of xanthine (Rajagopalan and Handler, 1967; Coughlan et al., 1969) and gives rise to a characteristic EPR signal attributable to $\mathrm{Mo}^{\mathrm{v}}$ (Aleman-Aleman et al., 1965). This signal, termed 'Inhibited' by Bray and Vanngard (1969), exhibits a doublet structure indicating that molybdenum is coupled to a single proton. The Inhibited signal generated by using $\mathrm{C}^{2} \mathrm{H}_{3} \mathrm{OH}$ does not show this doublet structure even when incubated in $\mathrm{H}_{2} \mathrm{O}$ for prolonged periods, indicating that the proton coupled to molybdenum in the signal-giving species is derived from the methanol itself and is not exchangeable with the bulk solvent (Pick et al., 1971). Dialysis at high temperatures or extremes in $\mathrm{pH}$, or incubation with $\mathrm{Na}_{2} \mathrm{~S}_{2} \mathrm{O}_{4}$ or $\mathrm{K}_{3} \mathrm{Fe}(\mathrm{CN})_{6}$ causes the Inhibited molybdenum $\mathrm{V}$ signal to disappear and at least partially restores activity. Unlike the other EPR signals of xanthine oxidase, the Inhibited signal is air stable.

Formaldehyde also produces the Inhibited signal with xanthine oxidase, and is able to do so in the absence of added xanthine (Pick et al., 1971). It is likely that methanol is converted to formaldehyde prior to its inactivation of the enzyme. Like methanol, formaldehyde is capable of reducing xanthine oxidase (Booth, 1938; Bray and Meriweather, 1966; Pick and Bray, 1969). Attack by persulfide (or any good nucleophile) on the carbonyl carbon of formaldehyde, in a reaction analogous to the first step of Fig. 6, might give rise to a structure with features consistent with the data (Fig. 10). This involvement of the persulfide would be in agreement with the observation that $\mathrm{NC}^{-}$and formaldehyde are mutually exclusive in their actions on the enzyme (Edmondson et al., 1972). Whatever the structure of the inactivated enzyme, it must provide sufficient stabilization of $\mathrm{Mo}^{\mathrm{v}}$ to account for the air-stability of the Inhibited EPR signal. This could be

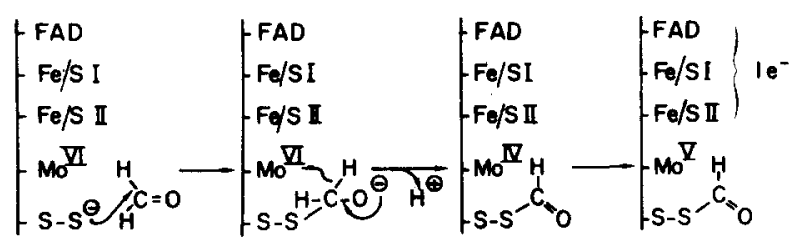

Fig. 10. Scheme proposed for the reaction of xanthine oxidase with formaldehyde giving rise to the enzyme species characterized by the Inhibited $\mathrm{Mo}^{\mathrm{v}}$ EPR signal. 
accomplished by raising the redox potential of $\mathrm{Mo}^{\mathrm{vi}}-\mathrm{Mo}^{\mathrm{v}}$ couple and/or lowering that of the flavin, where reaction with oxygen takes place.

Ethylene glycol (Tanner and Bray, 1978a,b) and mercaptoethanol (R. Hille, unpublished results) also inhibit xanthine oxidase and are capable of transferring reducing equivalents to it. The former has been shown to be converted to glyoxylate and oxalate by the enzyme (Tanner and Bray, 1978) and give rise to an EPR signal identical to the Inhibited signal except for the absence of doublet structre. This absence of splitting is consistent with the observation that the products expected to be involved in inactivation, glyoxylate and/or oxalate, contain only one carbonyl proton, which would be lost in the course of inactivation.

\subsection{ARSENITE}

Inhibition of xanthine oxidase by arsenite was first reported by Mackler et al. (1954). It was also studied briefly by Peters and Sanadi (1961). The importance of the arsenite inhibition to our understanding of the mechanism of xanthine oxidase did not become clear until Coughlan et al. (1969) reported that arsenite treatment, like cyanide, resulted in a spectral change of the enzyme which was coincident with the development of inhibition. They also made the important finding that cyanide and arsenite inhibition are mutually exclusive; prior reaction with cyanide prevents the appearance of the spectral changes typical of arsenite inhibition, and conversely, prior complexing with arsenite severely interferes with cyanide inactivation. The important observation was also made that whereas cyanide inactivation appeared to be irreversible (but see earlier section of cyanide inactivation), the effect of arsenite was reversible by dilution, e.g. by dialysis. They noted also that while the inhibition of xanthine oxidase by arsenite was a slow process, the closely related enzyme, liver aldehyde oxidase, was inhibited immediately $(<10 \mathrm{sec})$ by $10^{-4} \mathrm{M}$ arsenite, and that this inhibition was reversed rapidly on dilution. Thus they concluded that the effects of arsenite and cyanide were mutually exclusive, and that they both interacted with the enzyme bound molybdenum. As described in the previous section, this concept was discredited by the discovery of the cyanolysable sulfur in this group of enzymes, and the demonstration that this particular sulfur atom was essential for normal catalysis (Massey and Edmondson, 1970). The mutually exclusive reactions of cyanide and arsenite were, however, confirmed, and it was proposed that the common factor was their interaction with the cyanolysable sulfur atom. This was shown experimentally by the linear relationship between catalytic activity, cyanolysable sulfur and the extinction change at $380 \mathrm{~nm}$ due to complex formation with arsenite. The same relationship has also been found to exist for the ability to bind rapdily alloxanthine and other pyrazolo[3,4-d]pyrimidines, and for rapid reduction of the enzyme by substrate (Edmondson et al., 1972). The great importance of the cyanolysable sulfur atom to the properties of the enzyme were thus immediately obvious. Of the various hypotheses put forward to account for the chemical nature of this sulfur atom, none is entirely satisfactory. Only that proposed by Massey and Edmondson (1970) deals straightforwardly with the inhibition by arsenite in a way with known precedents, i.e. the strong complexing of arsenite with vicinal thiols. However, a point which has perhaps not received the attention it deserves, is the slowness of the reactions of cyanide and arsenite with milk xanthine oxidase (Coughlan, et al., 1969; Massey and Edmondson, 1970). This suggests that the form(s) of the enzyme reacting with these reagents may be minor equilibrium species. In this respect it is intriguing that aldehyde oxidase reacts rapidly with both cyanide and arsenite (Coughlan et al., 1969) and that all preparations so far reported show substantial amounts of a $\mathrm{Mo}^{\mathrm{v}}$ EPR signal in the resting enzyme (Rajagopalan et al., 1968).

\section{REFERENCES}

Alema.v-Aleman. V.. Rajagopalan, K. V., Handler, P. Beinert, H. and Palmer, G. (1965) On the mechanism of action of metalloflavoprotein. In: Oxidases and Related Redox Systems pp. 380-399, KING. T. E.. MAsON. 
H. S. and Morrison, M.. (Eds). Proceedings of a Symposium held in Amherst. Massachusetts. 1964, John Wilcy. New York.

BAKrk, B. R. and KormA, V. A. (1968) Irreversible enzyme and inhibitors. CXXV. Active-site-directed irreversible inhibitors of xanthine oxidase derived from arylpurines and pyrazolo[3,4-d]pyrimidines bearing a terminal sulfonyl fluoride. J. Med. Chem. $11: 656-661$

BAKER. B. R. and WOOD, W. F. (1967) Irreversible enzyme inhibitors. CII. On the mode of phenyl binding of 9-phenylguanine to guanine deaminase and xanthine oxidase. J. Med. Chem. 10: 1101-1105.

BAKI:R. B. R. and WoOD. W. F. (1968a) Irreversible enzyme inhibitors. CXXII. On the nature and dimensions of the hydrophobic bonding region of guanine deaminase and xanthine oxidase. J. Med.Chem. 11:644-649.

BAKER, B. R. and WOOD. W. F. (1968b) Irreversible enzyme inhibitors. CXXIII. Candidate irreversible inhibitors of guanine deaminase and xanthine oxidase derived from 9-phenylguanine substituted with a terminal sulfonyl fluoride. J. Med. Chem. 11: 650-652.

BAKt:k, B. R., WOOD. W. F. and KoEma, V. A. (1968) Irreversible enzyme inhibitors CXXVI. Hydrocarbon interaction with xanthine oxidase by phenyl substitutents on purines and pyrazolo[3,4-d]pyrimidines. $J$. Med. Chem. $11: 661-666$.

Balidwin. J. J., Kasinger, P. A.. Novello, F. C. Sprague, J. M. and Duggan, D. E. (1975) 4-Trifluoromethylimidazoles and 5-(4-pyridyi)-1.2,4-triazoles. new classes of xanthine oxidase inhibitors. J. Med. Chem. 18: $895-900$.

Baldwin, J. J.. lumma, P. K.. Novello, F. C.. Ponticello, G. S.. Sprague, J. M. and Duggan, D. E. (1977) 2-Pyridylimidazoles as inhibitors of xanthine oxidase. J. Med. Chem. 20: 1189-1193.

Berg. J. M.. Hodgson. K. O.. Cramer, S. P.. Corbin, J. L.. Elsberg, A.. Periyadath, N. and Stiefel. E. I. (1979) Structural results relevant to the molybdenum sites in xanthine oxidase and sulfite oxidase. Crystal structure of $\mathrm{MoO}_{2} \mathrm{~L}: \mathrm{L}=\left(\mathrm{SCH}_{2} \mathrm{CH}_{2}\right) \mathrm{NCH}_{2} \mathrm{CH}_{2} \mathrm{X}$ and $\mathrm{X}=\mathrm{SCH}_{3} . \mathrm{N}\left(\mathrm{CH}_{3}\right)_{2} . J$. Am. Chem. Soc.. 101: 2774. 2776

Booth. V. H. (1938) The xanthine oxidase-aldehyde system. Biochem. J. 32: 503--507.

Bordas. J., Bray, R. C.. Garner. C. D., Gutteridge, S. and Hasnain, S. S. (1980) X-ray absorption spectroscopy of xanthine oxidase. Biochem. J. 191: 499-508.

Bray. R. C. (1975) Molybdenum iron-sulfur flavin hydroxylases and related enzymes. In: The Enzymes Vol. XII pp. 300-419. Boyer. P. D. (Ed). Academic Press. New York

Bray. R. C.. Gutterdige. S.. Stotter. D. A. and Tanner. S. J. (1979) The mechanism of action of xanthine oxidase. Biochem. J. 177: 357-360.

Bray, R. C. and Mi:Riweather. L. S. (1966) Electron spin resonance of xanthine oxidase substituted with molybdenum-95. Natwe (London) 212: 467-469.

BRAY. R. C. and VANicard. T. (1969) "Rapidly Appearing" Molybdenum electron-paramagnetic resonance signals from reduced xanthine oxidase. Biochem. J. 114: 725-734.

CAMmACK. R.. Barber. M. J. and Bray. R. C. (1976) Oxidation-reduction potentials of molybdenum. flavin and iron-sulfur centres in milk xanthine oxidase. Biochem. $J$. 157: 469-478.

CHA. S. (1975) Tight-binding inhibitors. I. Kinetic behavior. Biochem. Pharmacol. 24: 2177-2185.

Cha. S. Agarwal. R. P. and Parks. R. E.. Jr. (1975) Tight-binding inhibitors. II. Non-steady state nature of inhibition of milk xanthine oxidase by allopurinol and alloxanthine and of erythrocytic adenosine deaminase by coformycin. Biochem. Pharmacol. 24: 2187-2197.

Chalmers. R. E.. Parkir. R.. Simmonds, H. A.. Snedden, W. and Watts, R. W. E. (1969) The conversion of 4-hydroxypyrazolo[3.4-d]pyrimidine (allopurinol) into 4,6-dihydroxypyrazolo[3,4-d]pyrimidine (oxipurinol) in tiro in the absence of xanthine oxygen oxidoreductase. Biochem. J. 112:527-532.

Colghtax. M. P. (1977) On the origin of the cyanolysable sulfur in molybdenum iron sulfur flavin hydroxylases. FEBS Lett. 81 : 1--6.

Colghlan. M. P.. Rajagopalan. K. V. and Handler. P. (1969). The role of molybdenum in xanthine oxidase and related enzymes. J. Biol. Chem. 244: 2658-2663.

Davis. M. D. (1980) Studies on the mechanism of action of xanthine oxidase. (Ph.D. Dissertation) University Microfilms Internation. Ann Arbor. Michigan.

Duggan. D. E.. Noll. R. M.. Baer, J. E.. Novello. F. C. and Baldwin. J. J. (1975) 5.5-Disubstituted 1.2.4-triazoles. a new class of xanthine oxidase inhibitor. J. Med. Chem. 18: 900-905.

Edmondson. D.. Balloc. D.. val Helvelen. A.. Palmer. G. and Massey. V. (1973) Kinetic studies on the substrate reduction of xanthine oxidase. J. Biol. Chem. 248: 6135-6144.

Edmondson. D., Massey, V.. Palmer. G.. Beacham. L. M. III and Elion. G. B. (1972) The resolution of active and inactive xanthine oxidase by affinity chromatography. J. Biol. Chem. 247: 1597-1604.

Elion. G. B. (1966) Enzymatic and metabolic studies with allopurinol. Ann. Rheum. Dis. 25: 608-614.

Elion. G. B.. Callaha.y. S.. Nathan. H.. Bieber. S.. Rundles. R. W. and Hitchings. G. H. (1963) Potentiation by inhibition of drug degradation: 6-substituted purines and xanthine oxidase. Biachem. Pharmacol. 12: 85-93.

Elion. G. B. Kovexsky. A., Hitchings. G. H.. Metz. E. and Rlndles. R. W. (1966) Metabolic studies of allopurinol. an inhibitor of xanthine oxidase. Biochem. Pharmacol. 15: 863-880.

Feigelson. P.. Davidson. J. D. and Robins. R. K. (1957) Pyrazolopyrimidines as inhibitors and substrates of xanthine oxidase. J. Biol. Chem. 266: 993-1000.

Fridovich. I. and Havdier. P. (1958) Xanthine oxidase. Il. Studies of the active site. J. Biol. Chem. 231 : $899-911$.

GOLDFINGER. S. E. (1971) Drug therapy: treatment of gout. N. Engl. J. Med. 285: 1303-1306.

GI'Tteridge. S.. TANNeR. S. J. and BRAY. R. C. (1978) Comparison of the molybdenum centres of native and desulpho xanthine oxidase. Biochem. J. 175: 887-897.

Hainilinf. B. E.. Johnson, J. L. and Rajagopalan. K. V. (1979) Isolation and properties of the molybdenum cofactor of xanthine oxidase and sulfite oxidase. Fed. Proc. 38: 314

Kalckar. H.. KieldgaARD. N. O and KlenOw. H. (1948) Inhibition of xanthine oxidase and related enzymes by 6-pteridylaldehyde. J. Biol. Chem. 174: 771-772. 
KalCKar, H. and KLENOW, H. (1948a) Milk xanthopterin oxidase and pteroylglutamic acid. J. Biol. Chem. 172: 349-350.

KalCKAR, H. and Klenow, H. (1948b) Enzymatic transformation of pteroylglutamic acid. J. Biol. Chem. 172: $351-352$.

KAPLAN, H. G. (1980) Inhibition of xanthine oxidase by folate analogues and derivatives. Biochem. Pharmacol. 29: $2135-2141$.

Ketchum, P. A., Cambier, H. Y., Frazier, W. A. III, Madansky, C. H. and Nason, A. (1970) In citro assembly of Neurospora assimilatory nitrate reductase from protein subunits of a Neurospora mutant and the xanthine oxidizing or aldehyde oxidase systems of higher animals. Proc. Nat. Acad. Sci. 66: $1016 \quad 1023$.

KomaI, H., Massey, V. and PaLmer, G. (1969) The preparation and properties of deflavo xanthine oxidase. $J$. Biol. Chem. 244: 1692-1700.

Krenitsky, T. A., Elion, G. B., Strelete, R. A. and Hitchings, G. H. (1967) Ribonucleosides of allopurinol and oxipurinol. J. Biol. Chem. 242: 2675-2682.

Lowry, O. H., Bessey, O. A. and Crawford, E. J. (1948) Pterin oxidase. J. Biol. Chem. 180: 399 - 410.

Mackler, B., Mahler, H. R. and Green, D. E. (1954) Studies on metalloflavoproteins. J. Biol. Chem. 210: 149-164.

MASSEY, V. (1973) Iron-sulfur flavoprotein hydroxylases. In: Iron-Sulfur Proteins Vol. I. pp. 301 360, LoviNBERG, W. (Ed.). Academic Press, New Y York.

Massey, V. and Edmondson, D. (1970) On the mechanism of inactivation of xanthine oxidase by cyanide. $J$. Biol. Chem. 245: 6595-6598.

Massey, V.. Komai, H., Palmer, G. and Elion, G. B. (1970a) On the mechanism of inactivation of xanthine oxidase by allopurinol and other pyrazolo[3,4-d]pyrimidines. J. Biol. Chem. 245: 2837-2844.

Massey, V., Komai, H., Palmer, G. and Elion, G. B. (1970b) The existence of nonfunctional sites in milk xanthine oxidase; reaction with functional active site inhibitors. Vitam. Horm. (N.Y.) 28: 505531.

McCollister, R. J., Gilbert, W. R.. JR., Ashton, D. M. and Wrngaarden, J. B. (1964) Pseudofeedback inhibition of purine synthesis by 6-mercaptopurine ribonucleotide and other purine analogues. J. Biol. Chem. 239: 1560-1568.

Nason, A., Lee, S.-S.P., Ketchum, P. A., Lamber Ti, A. and De Vrifs, J. (1971) In citro formation of assimilatory reduced nicotimamide adenine dinucleotide phosphate: nitrate reductase from a Neurospora mutant and a component of molybdenum-enzymes. Proc. Nat. Acad. Sci. 68: 3242-3246.

Olson, J. S., Ballou, D. P., Palmer, G. and Massey, V. (1974) The mechanism of action of xanthine oxidase. $J$. Biol. Chent. 249: 4363-4382.

OSTER, K. A. (1976) Folic acid and xanthine oxidase Ann. Intern. Med. 86: 367.

Peters, J. M. and SANADI, D. R. (1961) Effect of arsenite and cadmium ions on xanthine oxidase. Arch. Biochem. Biophys. 93: $312 \cdots 313$.

PICK, F. M. and Bray, R. C. (1969) Complex formation between reduced xanthine oxidase and purine substrates demonstrated by electron paramagnetic resonance. Biochem. $J$. 114: 735- 742.

PICK, F. M. and BraY, R. C. (1969) Complex formation between reduced xanthine oxidase and purine substrates demonstrated by electron paramagnetic resonance. Biochem. J. 114: 735- 742.

Pick. F. M.. MCGartoll, M. A. and Bray, R. C. (1971) Reaction of formaldehyde and of methanol with xanthine oxidase. Eur. J. Biochem. 18: 65-72

Rajagopalan, K. V. and Handler, P. (1964) Hepatic aldehyde oxidase. III. The substrate-binding site. J. Biol. Chem. 239: 2027-2035.

Rajagopalan, K. V. and Handler, P. (1967) Purification and properties of chicken liver xanthine dehydrogenase. J. Biol. Chem. 242: 4097-4107.

Rajagopalan, K. V., Handler, P., Palmer, G. and Beinert, H. (1968) Studies of aldehyde oxidase by electron paramagnetic resonance spectroscopy. J. Biol. Chem. 243: 3784-3796.

Rlindles, R. W., Wyngaarden, J. B., Hitchings, G. H. and Elion, G. B. (1969) Drugs and uric acid. Annu. Ret. Pharmacol. 9: 345-362.

Rundles, R. W., Wyvgaarden, J. B., Hitchings, G. H., Elion, G. B. and Silberman, H. R. (1963) Effects of a xanthine oxidase inhibitor on thiopurine metabolism, hyperuricemia and gout. Trans. Assoc. Am. Physicians 76 : $126-140$.

Smith, D. J., MagGio, E. T. and KeNyon, G. L. (1975) Simple alkane-thiol groups for temporary blocking of sulfhydryl groups of enzymes. Biochemistry 14: 766-771.

SPECTOR, T. J. and JOHNS, D. J. (1970) Stoichiometric inhibition of reduced xanthine oxidase by hydroxypyrazolo[3,4-d]pyrimidines. J. Biol. Chem. 245: 5079-5085.

Springer, R. H., Dimmitt, M. K., Novinson, T., O'Brien, D. E., Robins, R. K., Simon, L. N. and Miller, J. P. (1976) Synthesis and enzymatic activity of some novel xanthine oxidase inhibitors. 3-Substituted 5,7-dihydroxypyrazolo[1.5-x]pyrimidines. J. Med. Chem. 19: 291-296.

Stiefel, E. J. (1977) The coordination and bioinorganic chemistry of molybdenum. Prog. Inorg. Chem. 22: $1-233$.

SZENT-GyORGYI, A. (1926) Uber die Wirkungsweise des Schardingerschen Ferments. Biochem. Z. 173: 275-278.

TANNER, S. J. and BRAY, R. C. (1978a) Ethylene glycol as a very slow substrate for xanthine oxidase. Biochem. Soc. Trans. 6: 1331-1333.

TANNER, S. J. and BRAY, R. C. (1978b) A new molybdenum electron-paramagnetic-resonance signal from treatment of functional xanthine oxidase with ethylene glycol. Biochem. Soc. Trans. 6: 1333-1335.

Tullius, T. D.. Kurtz, D. M., Jr., Conradson, S. D. and Hodgson, K. O. (1979) The molybdenum site of xanthine oxidase. Structural evidence from X-ray absorption spectroscopy. J. Am. Chem. Soc. 101: 2776-2779.

YU, T.-F. and Cutman, A. B. (1964) Effect of allopurinol (4-hydroxypyrazolo[3,4-d]pyrimidine) on serum and urinary uric acid in primary and secondary gout. Am. J. Med. 37: 885-898. 